\title{
Complementary Person-Environment Fit as a Predictor of Job Pursuit Intentions in the Service Industry
}

\author{
Marlena A. Bednarska ${ }^{1}$
}

ABSTRACT

There is an intrinsic link between the success of service firms and the availability of appropriate labor resources, making employee attraction and retention a critical concern for service organizations. Effects of recruitment efforts are influenced by applicants'subjective person-environment (P-E) fit, referring to the compatibility between an individual and a work environment. The purpose of this paper is to examine the role of employer attractiveness in the relationship between potential employees' perceptions of P-E fit and job pursuit intentions in the service industry. This study was conducted with a group of 335 undergraduates and graduates enrolled in tourism and hospitality studies in Poznan. Data were collected through group-administered questionnaires. Research revealed that students generally did not believe that a career in the hospitality sector would fulfill their needs, rating job attributes slightly higher than organization attributes. Regression analyses showed that both person-job (P-J) fit and person-organization (P-O) fit were positively related to intentions to apply for a job, with the former being a stronger predictor. The relationship under study was fully mediated by the perceived attractiveness of hospitality employers. The findings contribute to an improved understanding of the influence of P-J and P-O fit on work-related attitudes and intentions of Generation Y prospective employees in the hospitality industry.

KEY WORDS: $\quad$ person-environment fit, employer attractiveness, job pursuit intentions, service industry, potential employees

JEL Classification: J24, L80

${ }^{1}$ Faculty of International Business and Economics, Poznan University of Economics and Business, Poland

\section{Introduction}

There is a broad consensus that the success of service firms in general and high-contact service firms in particular lies to a great extent in the quality of their human resources. It has been argued that the ultimate source

-

Correspondence concerning this article should be addressed to: Marlena A. Bednarska Faculty of International Business and Economics, Poznan University of Economics and Business, Poland Al. Niepodleglosci 10, 61-875 Poznan, Poland tel. (+4861) 8543762 E-mail:m.bednarska@ue.poznan.pl of value creation is operant resources - employees' knowledge, skills, and abilities utilized to create a differentiated and valued offering in the marketplace (Andreassen \& Lanseng, 2010; Lusch, Vargo, \& O’Brien, 2007). Therefore, the issue of attracting and retaining qualified and engaged employees is of critical importance for service organizations. The perception of organization attractiveness as a workplace is determined by job searchers' subjective appraisal of the interaction between them and the work environment. If potential employees find value congruence and a match between 
their personal abilities and needs and the job and organization demands and supplies, they are more likely to have positive attitudes towards being employed by a company, to declare an acceptance intention if a job were to be offered, and to make the decision to pursue a firm as a place of work (Cable \& Judge, 1996; Carless, 2005; Kristof-Brown, Zimmerman, \& Johnson, 2005).

Given the importance of person-environment (PE) fit for the success of an organization's recruitment efforts, it is essential for service enterprises to obtain a clear picture of the preferences of future workers and locate any incorrect beliefs that potential employees might hold. Furthermore, due to growing generational diversity among the current workforce, with Generation Y making up an increasingly larger percentage of employees, service companies should find solutions for attracting Millennial candidates. Accommodating the needs of this cohort seems to be a challenge, as this group is believed to approach employment in a manner different from that of their predecessors (Bednarska \& Olszewski, 2014; Hershatter \& Epstein, 2010). Nevertheless, understanding the values that younger generations bring to work appears essential for those who wish to remain competitive in attracting qualified applicants (Cogin, 2012). Although P-E fit has received much interest from researchers over the past several decades, the understanding of the phenomenon is based primarily on studies conducted in North America (Oh et al., 2014). Additionally, greater attention has been paid to exploring the consequences of fit during post-hire stages (Jansen \& Kristof-Brown, 2006). The present paper addresses these shortcomings by investigating the role of P-E fit in the job choice process of Generation $\mathrm{Y}$ in the context of Poland.

The objective of the paper is to examine the role of employer attractiveness in the relationship between potential employees' perceptions of complementary P-E fit and job pursuit intentions in the service industry. The empirical investigation is limited to a single industry, namely, hospitality. To reach the objective proposed, the paper proceeds as follows. First, the concept of P-E fit and its outcomes are discussed on the basis of the existing literature. Next, the research methodology and findings of the study on students' attitudes and intentions towards careers in the hospitality industry are presented. Finally, implications and guidelines for future research are proposed.

\section{Literature review and hypothesis development}

The domain of interaction between workers and the environments in which they function has been prevalent in management research for decades. In general, P-E fit refers to the congruence, match, or similarity between the person and the environment. These terms denote the proximity of the person and the environment to each other (Edwards, 2008). The broad construct of P-E fit can be distinguished in terms of supplementary fit and complementary fit (Kristof, 1996). Supplementary fit exists when the person possesses characteristics that are similar to others in the environment. Complementary fit occurs when the person's characteristics fill a gap in the environment or vice versa. It encompasses both the need-supply fit, defined as the degree to which the needs of the individual are fulfilled by rewards in the environment, and the demand-ability fit, defined as the degree to which the needs of the environment are fulfilled by the capabilities of the individual (Kristof, 1996).

Strategies for fit operationalization also vary widely. Edwards et al. (2006) distinguish three basic approaches to studying P-E fit: atomistic, molecular, and molar. The atomistic approach examines perceptions of the person and the environment as separate entities and then compares them. The molecular approach concerns the perceived discrepancy between the person and the environment and preserves the direction of the difference. The molar approach focuses on the perceived similarity between the person and the environment and disregards the direction of the difference. As noted by Kristof-Brown et al. (2005), P-E fit can be assessed directly, based on perceived compatibility, or indirectly, based on actual compatibility of separately rated variables. The latter can be differentiated into subjective fit, if the variables are reported by a single source, and objective fit, if the variables are reported by different sources.

P-E fit has been the subject of a large number of studies. However, as both people and the environments they inhabit are multidimensional, researchers have been faced with the problem of capturing all the fit forms (Edwards \& Billsberry, 2010). Scholars investigated the fit between employees and their vocations (Feij et al., 1999; Marcus \& Wagner, 2015), jobs (Babakus, Yavas, \& Ashill, 2011; Chen, Yen, \& 
Tsai, 2014), teams (Glew, 2012), work groups (Seong \& Kristof-Brown, 2012; Werbel \& Johnson, 2001), supervisors (Kim \& Kim, 2013), organizations (Piasentin \& Chapman, 2007; Swider, Zimmerman, \& Barrick, 2015), cultures (Nazir, 2005), and locations (Solnet et al., 2014). Consequently, P-E fit is generally considered to be a multidimensional concept (Edwards \& Billsberry, 2010; Jansen \& Kristof-Brown, 2006; Wheeler et al., 2005).

The substantial stream of research on the compatibility between individuals and their work environments used two-factor conceptualization and focused on person-job (P-J) and person-organization (P-O) fits. P-J fit refers to the relationship between the individual's characteristics and those of the tasks that are performed at work. P-O fit addresses the compatibility between the individual and the organization as a whole (Kristof-Brown et al., 2005).

A growing body of empirical evidence supports the notion that fit between employees and their work environments affects both pre-entry and post-entry attitudes, intentions, and behaviors in the workplace. Recent meta-analytic studies (Kristof-Brown et al., 2005; Oh et al., 2014) confirmed that P-J and P-O fit had a significant relationship with outcomes reported by prospective employees (organizational attraction and job acceptance), employing organizations (intent to hire and job offers), and actual employees (job satisfaction, organizational identification, organizational commitment, job performance, and intent to quit).

The focus of this paper is on the complementary form of need-supply fit, which was found to have the greatest impact on individual attitudes and behaviors (Kristof-Brown et al., 2005; Schmidt, Chapman, \& Jones, 2015). The primary mechanism by which needsupply fit shapes attitudinal outcomes can be explained by theories of psychological need fulfillment (Cable \& Edwards, 2004). These theories posit that employees' attitudes are affected by a cognitive comparison of the desired amount of reward relative to the amount that is perceived to be supplied in the work environment. As the degree to which employees' desires are met increases, the positive attitudes they will experience towards the employer increase.

Another theoretical guide for investigating complementary fit outcomes is offered by the theory of reasoned action and the theory of planned behavior, with the latter being the extension of the former (Ajzen, 1991; Fishbein \& Ajzen, 1975). In general, these theories assume that an individual's beliefs about an object manifest into attitudes towards behaviors related to this object; attitudes are then expected to influence intentions to engage in these behaviors, which predict subsequent behaviors. Applied to the job choice context, the primary antecedent of job pursuit behavior is the intention to pursue the job in question. The intention to apply for the job in a given company, in turn, is a function of the perception of this company's attractiveness as an employer, which is affected by subjective assessment of the match between the individual and the work environment.

The outcome variables that have received the most attention in research on pre-entry fit perceptions are employer attraction (attractiveness) and job pursuit intentions. The former construct reflects the degree to which a prospective employee finds an employer a desirable place to work, and the latter, his or her willingness to enter or stay in the applicant pool. Although some researchers combine attitudinal and intentional measures to assess applicant attraction (e.g., Judge \& Cable, 1997; Harold \& Ployhart, 2008), for the purpose of this study, the attractiveness of the employer and the intentions to pursue a job are treated as distinct constructs. While attractiveness refers to a passive affect towards a potential relationship with a company as a place of employment, job pursuit intentions require an active engagement of an applicant (Aiman-Smith, Bauer, \& Cable, 2001; Highhouse, Lievens, \& Sinar, 2003).

Based on the above discussion, the following hypotheses are developed:

Hypothesis 1: P-E fit is positively related to employer attractiveness.

Hypothesis 2: Employer attractiveness is positively related to job pursuit intentions.

Hypothesis 3: Employer attractiveness mediates the effect of P-E fit on job pursuit intentions.

These hypotheses are summarized in the model presented in Figure 1.

In early recruitment stages, applicants have only some elementary knowledge of potential jobs and organizations, which they generate for future consideration. Consequently, initial intentions to pursue employment opportunities at a particular firm are based on 


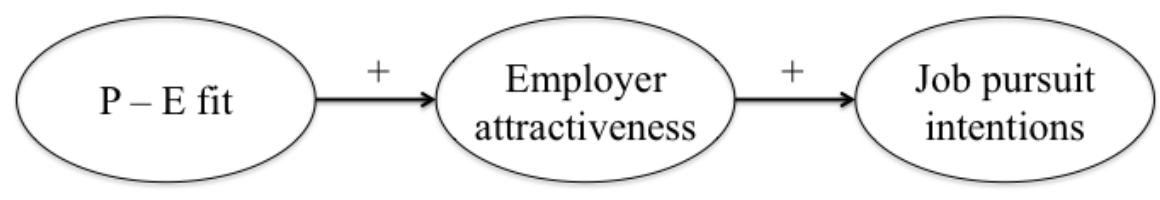

Figure 1. Hypothesized model

Table 1. Respondent profile

\begin{tabular}{llcc}
\hline Variable & Category & N & Share [\%] \\
\hline \multirow{2}{*}{ Gender } & Female & 230 & 68.9 \\
& Male & 104 & 31.1 \\
\hline \multirow{2}{*}{ Age } & 20 and younger & 120 & 35.9 \\
& $21-22$ & 125 & 37.4 \\
& $23-24$ & 67 & 20.1 \\
\hline \multirow{2}{*}{ Study degree } & 25 and older & 22 & 6.6 \\
\hline \multirow{2}{*}{ Study mode } & Bachelor's & 256 & 76.6 \\
\hline \multirow{2}{*}{ Type of school } & Master's & 78 & 23.4 \\
\hline Full time & Part time & 273 & 81.7 \\
Work experience & Public & 61 & 18.3 \\
\hline Work experience in hospitality & Non-public & 251 & 74.9 \\
\hline & Yes & 84 & 25.1 \\
\hline
\end{tabular}

general impressions of employer attractiveness, which are affected by the industry in which the firm operates. Additionally, as the applicants' familiarity with a company decreases, the frequency with which they use general industry perceptions to form impressions of a specific organization increases (Burmann, Schaefer, \& Maloney, 2008; Wilden, Gudergan, \& Lings, 2010). This situation is fairly common in service sectors, which are fragmented and dominated by smalland medium-sized enterprises. Given the importance of the industry image in regard to the evaluation of potential employers, the need to explore prospective employees' beliefs about their fit with jobs and organizations in a particular industry is becoming evident.

\section{Research method}

To reach the objective of the study, field investigation was conducted. The target population comprised undergraduates and graduates enrolled in tourism and hospitality studies in universities in Poznan, Poland. At the time of data collection (academic year 2012/2013), eight public and private higher 
Table 2. Factor loadings for items

\begin{tabular}{lcc}
\hline & & Factor loadings \\
Items & $\mathbf{1 .}$ & $\mathbf{2}$. \\
\cline { 2 - 3 } Stable employment conditions & .822 & .796 \\
Feeling of trust and cooperation in the workplace & .781 \\
Friendly atmosphere & .780 \\
Opportunities of enhancing qualifications & .769 \\
Integration and belonging & .751 \\
Work-life balance & .734 \\
Attractive fringe benefits & .723 \\
Good prospects for promotion within the organization & .712 \\
Good prospects for long-term professional development & .696 \\
Competent supervisors & .686 \\
High salary & .538 \\
Experience for future employment & \\
Challenging tasks & \\
Matching individual interests & \\
Variety of work activities & & .837 \\
\hline
\end{tabular}

Table 3. Summary of exploratory factor analysis

\begin{tabular}{lcccc}
\hline Factors & Number of items & Eigenvalue & Variance explained & Cronbach's alpha \\
\hline 1. Person-organization fit & 12 & 7.825 & $44.26 \%$ & .935 \\
2. Person-job fit & 3 & 1.268 & $16.36 \%$ & .691 \\
\hline
\end{tabular}

education institutions in Poznan offered bachelor's and master's degrees in tourism, and a total of 4150 students took tourism and hospitality courses. To obtain a representative subset of the target population, a random sampling process was employed, specifically, a single-stage cluster sampling. Tourism and hospitality course providers were contacted, and they all agreed to facilitate access to their students. Data were collected through group-administered paperbased questionnaires distributed during a regularly scheduled class period. The sample accounted for 348 respondents, yielding a response rate of $66 \%$. Due to incomplete or incoherent information, 13 questionnaires were excluded, which resulted in 335 usable questionnaires for further analysis. The sample was demographically diverse - the age span of the respondents was 18 to 45 years old, with a mean age of 22 , and $69 \%$ of them were female. Of the respondents, $77 \%$ were pursuing a bachelor's degree, and the sample was dominated by full-time students $(82 \%)$. The majority of students had work experience (82\%), and $50 \%$ of them worked in the hospitality industry. Table 1 shows descriptive statistics for the sample.

A questionnaire designed for the purpose of this study was developed based on a review of previous investigations on complementary P-E fit and employer attractiveness. Measures used in the survey were adapted from multiple resources (Bednarska \& Olszewski, 2013; Boon et al., 2011; Cable \& Edwards, 2004; Schlager et al., 2011). 
Table 4. Variable descriptive statistics and correlations

\begin{tabular}{lcccccccc}
\hline \multirow{2}{*}{ Variables } & M & SD & \multicolumn{7}{c}{ Correlations } \\
\cline { 6 - 9 } & & & 1. & 2. & 3. & 4. & 5. & 6. \\
\hline 1. Age & 21.632 & 2.553 & & & & & & \\
2. Gender & 0.689 & 0.464 & -.105 & & & & & \\
3. Experience in hospitality & 0.500 & 0.501 & $.130^{*}$ & .022 & & & & \\
4. Person-organization fit & -1.199 & 1.020 & $-.207^{* *}$ & -.018 & -.052 & & & \\
5. Person-job fit & -1.018 & 1.290 & -.091 & .052 & .054 & $.523^{* *}$ & & \\
6. Employer attractiveness & 4.643 & 1.474 & -.080 & $.137^{*}$ & $.211^{* *}$ & $.362^{* *}$ & $.530^{* *}$ & \\
7. Job pursuit intentions & 4.223 & 1.830 & $-.139^{*}$ & .103 & $.185^{* *}$ & $.281^{* *}$ & $.402^{* *}$ & $.658^{* *}$ \\
\hline
\end{tabular}

Note: Gender: $0=$ male, $1=$ female; Experience in hospitality: $0=$ no, $1=y e s$

Significant at ${ }^{*} p<0.05 ;{ }^{* *} p<0.01$ (2-tailed).

The research instrument consisted of four main components. Respondents were requested first to imagine an ideal employer for whom they would choose to work and to evaluate 15 job and organizational attributes based on their expectations. Afterwards, they were asked to assess the analyzed attributes regarding employers in the hospitality industry. This approach allows an evaluation of the need-supply fit, and it is in line with an atomistic strategy for measuring fit. The data enabled the computation of the gaps between preferred and perceived job/organization attributes, which were independent variables in the study. The gap was calculated as a difference between perception and expectation for desired attributes and as a difference between expectation and perception for undesired attributes (Bednarska \& Olszewski, 2013). Accordingly, a positive number denotes exceeded expectations, and a negative number denotes unmet expectations. In the third section, two outcomes of P-E fit were investigated - the hospitality industry's attractiveness as an employer and the intention to apply for a job in the hospitality industry. Both outcomes were assessed using single-item measures ("I find being employed in the hospitality industry an interesting option" and "I plan to apply for a job in the hospitality industry"). Although the validity of single-item scales is a subject of constant debate, such measures are deemed appropriate for concrete objects and attributes of the underlying construct (Bergkvist \& Rossiter, 2007). The inquiry form contained closed-ended questions, and for gradations of opinions, a seven-point Likert scale was utilized, ranging from "strongly disagree" (1) to "strongly agree" (7). In the final section, demographic data were collected.

\section{Analysis and results}

In order to confirm the dimensionality of the questionnaire and to guarantee that each variable constituted an independent construct, an exploratory factor analysis was conducted, using principal component extraction with varimax rotation. Both the Kaiser-Meyer-Olkin measure of sampling adequacy (0.92) and Bartlett's test of sphericity $\left(\chi^{2}=1195.88\right.$, $\mathrm{p}<0.001)$ suggested that factor analysis was appropriate for the data collected. The results of this procedure are reported in Tables 2 and 3. The analysis produced two factors with eigenvalues greater than 1.0, which explained $61 \%$ of the total variance. Although a reliability coefficient (Cronbach's alpha) for P-J fit was lower than the generally accepted minimum level of 0.7 , the construct was retained, as for scales with a small number of items, a smaller alpha is considered permissible (Nunnally \& Bernstein, 1994).

Means, standard deviations, and correlations between the variables of interest are presented in Table 4. The independent variables scores were computed by averaging the items that constitute the relevant dimension. The picture that emerges from the table is that the students generally did not believe that a career in the hospitality sector would fulfill their needs, 


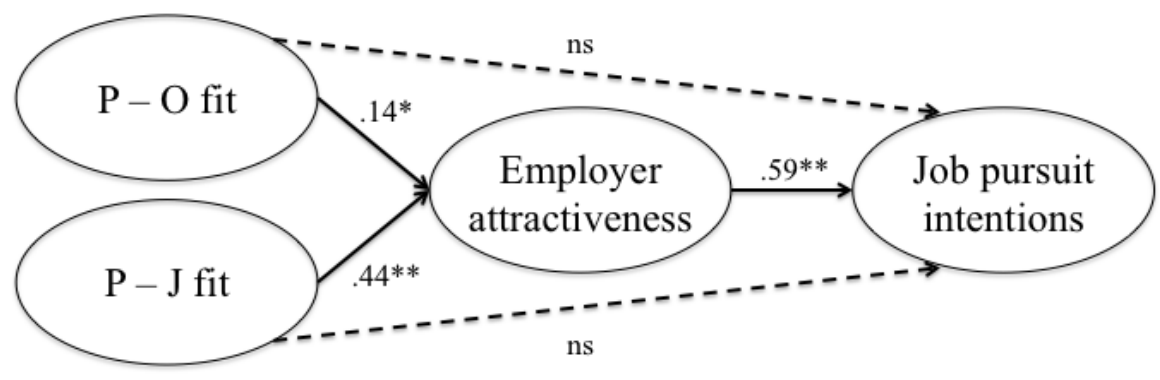

Figure 2. Research model results

Standardized beta coefficients are provided

Significant at ${ }^{*} p<0.05 ;{ }^{* *} p<0.01$; ns $=$ non-significant

with job attributes being rated slightly higher than organization attributes. Both P-J and P-O fit showed statistically significant positive correlations with industry attractiveness as an employer and with job pursuit intentions, with P-J fit displaying a stronger relationship with them.

To investigate the outcomes of P-E fit, multiple regression analyses were performed. Specifically, to test hypothesis 1 , employer attractiveness was regressed on P-J and P-O fit; to test hypothesis 2, job pursuit intentions were regressed on employer attractiveness. In both cases, demographic variables were entered in the first step of the analysis to control for the potentially confounding effects of age, gender, and work experience gained in the hospitality industry. As shown in Table 5, the results indicated that there were significant positive relations between employer attractiveness and P-J and P-O fit (model 1) and between job pursuit intentions and employer attractiveness (model 2) after controlling for demographics. Thus, hypotheses 1 and 2 were supported.

Additionally, this study tested the hypothesis that employer attractiveness mediates the positive relationship between complementary P-J and P-O fit and the intention to apply for a job. To test the mediating effects of perceived employer attractiveness, Baron and Kenny's (1986) recommended procedures were applied. First, the relationship between P-J and P-O fit (predictors) and job pursuit intentions (outcome) was examined. Second, employer attractiveness (mediator) was related both to P-J and P-O fit and to job pursuit intentions (hypothesis 1 and 2 testing). Finally, the effects of P-J and P-O fit on job pursuit intentions, controlling for employer attractiveness, were tested. The results of regression analyses are displayed in Table 6. As shown in model 1, both P-J and P-O fit were significantly and positively related to intentions to apply for a job, with the former being a stronger predictor. As presented in model 2, when perceived employer attractiveness was added to the regression model, the antecedents explained $44 \%$ of the variance in intentions to apply for a job (compared to $21 \%$ without a mediator), and relationships between P-J and P-O fit and job pursuit intentions were no longer significant. Thus, the findings reveal that the conditions for full mediation were met. The Sobel test $(\mathrm{Z}=2.48, \mathrm{p}<0.05$, for $\mathrm{P}-\mathrm{O}$ fit; $\mathrm{Z}=6.70, \mathrm{p}<0.001$, for P-J fit) indicates that the indirect effects under study were significant, thus providing support for hypothesis 3. The results are illustrated in Figure 2.

In summary, the empirical evidence supports positive indirect links between the complementary P-E fit and job pursuit intentions of Generation $\mathrm{Y}$ in the hospitality industry. That is, P-E fit must first increase perceived employer attractiveness in order to then strengthen the intentions to apply for a job.

\section{Discussion}

Although abundant research involved various areas of fit between employees and their work environments, relatively few studies to date have focused on 
Table 5. Results of regression analyses: employer attractiveness as a dependent variable (model 1) and as an independent variable (model 2)

\begin{tabular}{|c|c|c|c|c|}
\hline \multirow[t]{2}{*}{ Variables } & \multicolumn{2}{|c|}{ Model 1 Employer attractiveness } & \multicolumn{2}{|c|}{ Model 2 Job pursuit intentions } \\
\hline & 1. & 2. & 1. & 2. \\
\hline \multicolumn{5}{|l|}{ Step 1 - control variables } \\
\hline Age & $-.093+$ & -.021 & $-.159 * *$ & $-.098^{*}$ \\
\hline Gender & $.126^{*}$ & $.107^{*}$ & $.092+$ & .014 \\
\hline Experience in hospitality & $.226^{* *}$ & $.203^{* *}$ & $.209^{* *}$ & .067 \\
\hline \multirow{4}{*}{$\begin{array}{l}\text { Step } 2 \text { - study variables } \\
\text { Person-organization fit } \\
\text { Person-job fit } \\
\text { Employer attractiveness }\end{array}$} & & & & \\
\hline & & $.138^{*}$ & & \\
\hline & & $.439^{* *}$ & & \\
\hline & & & & $.636^{* *}$ \\
\hline $\mathrm{R}^{2}$ & .074 & .344 & .073 & .448 \\
\hline Adj. $R^{2}$ & .065 & .334 & .064 & .442 \\
\hline$\Delta R^{2}$ & & $.270^{* *}$ & & $.375^{* *}$ \\
\hline $\mathrm{F}$ & $8.631^{* *}$ & $33.777^{* *}$ & $8.556^{* *}$ & $66.032^{* *}$ \\
\hline
\end{tabular}

Note: Standardized beta coefficients are provided

Significant at $+p<0.1 ;{ }^{*} p<0.05 ;{ }^{* *} p<0.01$.

pre-entry P-E fit perceptions and their consequences for the job search behavior of Millennials. Additionally, despite calls for a multidimensional approach to studying fit, the majority of past research evaluated the fit between an individual and a single aspect of the work environment (Jansen \& Kristof-Brown, 2006). The present study, therefore, aims to address this gap by investigating the simultaneous effects of complementary P-J and P-O fit perceived by prospective employees from Generation $\mathrm{Y}$ on job pursuit intentions in one of the service industries - hospitality. Moreover, unlike most empirical research on the topic, this study does not consider beliefs, attitudes, and intentions related to the specific organization but rather to the industry as a career field.

The findings provide empirical validation for the proposed model; in particular, the results showed that subjective P-E fit influenced intentions to apply for a job indirectly via employer attractiveness. As the degree to which the needs of prospective employees were perceived to be fulfilled by rewards in the given industry increased, the industry was found to be more attractive as a potential place for employment. As candi- dates' opinion of the industry as an employer became more favorable, their intentions to apply for a job in that industry strengthened. The relations between the variables are consistent with the propositions of theories of reasoned action and planned behavior. The results correspond with those obtained in prior research conducted among actual job applicants (Carless, 2005; Phillips et al., 2014).

The study's findings also showed that complementary P-J fit tended to display a stronger relationship with the perceived attractiveness of the industry as a workplace and job pursuit intentions, compared to $\mathrm{P}-\mathrm{O}$ fit. This finding suggests that Millennial potential employees are more interested in ensuring that the job they choose is congruent with their requirements rather than working in an organization that satisfies their needs. This observation is in line with Jansen and Kristof-Brown's (2006) proposition, which claims that the salience of fit with different aspects of the environment is affected by the temporal stage of work experience. At early stages of the pre-hire phase, P-J fit is more salient than P-O fit. Similar findings in the graduate applicant context were reported by Carless (2005). 
Table 6. Results of regression analyses: employer attractiveness as a mediating variable

\begin{tabular}{|c|c|c|c|c|}
\hline \multirow[t]{2}{*}{ Variables } & \multicolumn{2}{|c|}{ Model 1 Job pursuit intentions } & \multicolumn{2}{|c|}{ Model 2 Job pursuit intentions } \\
\hline & 1. & 2. & 1. & 2. \\
\hline \multicolumn{5}{|l|}{ Step 1 - control variables } \\
\hline Age & $-.159^{* *}$ & $-.106^{*}$ & $-.157^{* *}$ & $-.091^{*}$ \\
\hline Gender & .085 & .075 & .088 & .012 \\
\hline Experience in hospitality & $.216^{* *}$ & $.196^{* *}$ & $.217^{* *}$ & $.078+$ \\
\hline \multicolumn{5}{|l|}{ Step 2 - study variables } \\
\hline Person-organization fit & & & & .015 \\
\hline Person-job fit & & $\begin{array}{l}.104+ \\
274^{* *}\end{array}$ & & .072 \\
\hline Employer attractiveness & & $.324^{* \star}$ & & $.591^{* *}$ \\
\hline$R^{2}$ & .074 & .222 & .075 & .454 \\
\hline Adj. $R^{2}$ & .065 & .210 & .066 & .443 \\
\hline$\Delta R^{2}$ & & $.148^{* *}$ & & $.379 * *$ \\
\hline $\mathrm{F}$ & $8.647^{* *}$ & $18.433^{* *}$ & $8.704^{* *}$ & $44.288^{* *}$ \\
\hline
\end{tabular}

Note: Standardized beta coefficients are provided

Significant at $+p<0.1 i^{*} p<0.05 ;^{* *} p<0.01$.

The findings of the present investigation have both research and practical implications. From a theoretical standpoint, the study demonstrates a vital function of the fit construct in the job search process; thus, it may bring added value to existing knowledge about the antecedents of potential employees' work-related attitudes and behavioral intentions in service industries. Additionally, the results extend current P-E fit research by addressing the notion of complementary fit and its outcomes at the industry level. Concerning suggestions for managerial practice, the results emphasize the importance of developing recruitment practices that are targeted to a specific group of candidates. It is critical for employers to be aware of age dissimilarities within the workforce and to realize that new entrants have different values and expectations. Service organizations seeking to attract Generation Y employees should ensure that applicants have sufficient information about the job to be able to evaluate their P-J fit. As the degree of perceived fit between an individual's characteristics and those of the tasks that are performed at work increases, the quantity of applicant pools increases and, consequently, the likelihood of recruiting high-quality candidates who would con- tribute to performance enhancement strengthens. If employers fail to deliver information that can be used to determine fit, they risk losing job seekers who selfselect out of the recruitment process.

The results of this study should be considered in light of its limitations. Although the use of a groupadministered survey was appropriate, given the objective of the investigation, it raises concerns about common method bias. Field study data were delivered by respondents, and self-reported data are prone to response bias, especially social desirability. In addition, all variables were measured based on the same source, which resulted in the subjective assessment of fit. However, it is argued that the subjective perception of match is particularly relevant in the context of job choice, as it represents an individual's direct judgment of how well he or she would fit in the work environment (Judge \& Cable, 1997). Another issue to keep in mind when interpreting the results is that this study used cross-sectional data to test the hypotheses, which means that the direction of causality cannot be unambiguously determined. However, this concern is mitigated in this context because the hypothesized relationships were based on logical grounds and on 
previous research relying on longitudinal data. In addition, the model focused on employer attractiveness as a mediating link. It would be of value to explore other possible mediating mechanisms between complementary fit and job pursuit intentions. It should also be noted that the outcome variables were measured with single-item scales, which is a source of a reliability assessment problem and may have attenuated observed relationships. Finally, a potential weakness of this inquiry arises from the unique characteristics of the population. Research was carried out in only one city among undergraduates and graduates enrolled in tourism and hospitality studies. Consequently, the findings may not be generalizable to a sample of other prospective employees who have more work experience and are in other stages of their careers. They also may not be wholly transferable to service environments not considered here. Therefore, further studies are needed to verify or repudiate these findings within different contexts.

\section{References}

Aiman-Smith, L., Bauer, T. N., \& Cable, D. M. (2001). Are you attracted? Do you intend to pursue? A recruiting policy-capturing study. Journal of Business and Psychology, 16 (2), 219-237.

Ajzen, I. (1991). The theory of planned behavior. Organizational behavior and human Decision Processes, 50 (2), 179-211.

Andreassen, T. W., \& Lanseng, E. J. (2010). Service differentiation: A self-image congruency perspective on brand building in the labor market. Journal of Service Management, 21 (2), 212-236.

Babakus, E., Yavas, U., \& Ashill, N. J. (2011). Service worker burnout and turnover intentions: Roles of person-job fit, servant leadership, and customer orientation. Services Marketing Quarterly, 32 (1), $17-31$.

Baron, R. M., \& Kenny, D. A. (1986). The moderatormediator variable distinction in social psychological research: Conceptual, strategic, and statistical considerations. Journal of Personality and Social Psychology, 51 (6), 1173-1182.

Bednarska, M., \& Olszewski, M. (2014). Pokolenie $\mathrm{Y}$ na turystycznym rynku pracy [Generation Y in the tourism labour market]. In B. Krakowiak
\& J. Latosińska (Eds.), Przeszłość, teraźniejszossć i przyszłość turystyki: warsztaty z geografii tury$z m u$ [Past, present and future of tourism: Workshop in tourism geography] (pp. 279-291). Łódź: Wydawnictwo Uniwersytetu Łódzkiego,

Bednarska, M. A., \& Olszewski, M. (2013). Organisational determinants of employer image: A case of the tourism industry in Poland. Anuario Turismo Y Sociedad, 14, 17-31.

Bergkvist, L. I., \& Rossiter, J. R. (2007). The predictive validity of multiple-item versus single-item measures of the same constructs. Journal of Marketing Research, 44 (2), 175-184.

Boon, C., Den Hartog, D. N., Boselie, P., \& Paauwe, J. (2011). The relationship between perceptions of HR practices and employee outcomes: Examining the role of person-organisation and person-job fit. International Journal of Human Resource Management, 22 (1), 138-162.

Burmann, C., Schaefer, K., \& Maloney, P. (2008). Industry image: Its impact on the brand image of potential employees. Journal of Brand Management, 15 (3), 157-176.

Cable, D. M., \& Edwards, J. R. (2004). Complementary and supplementary fit: A theoretical and empirical integration. Journal of Applied Psychology, 89 (5), 822-834.

Cable, D. M., \& Judge, T. A. (1996). Person - organization fit, job choice decision, and organizational entry. Organizational Behavior and Human Decision Processes, 67 (3), 294-311.

Carless, S. A. (2005). Person-job fit versus personorganization fit as predictors of organizational attraction and job acceptance intentions: A longitudinal study. Journal of Occupational and Organizational Psychology, 78 (3), 411-429.

Chen, C. Y., Yen, C. H., \& Tsai, F. C. (2014). Job crafting and job engagement: The mediating role of person-job fit. International Journal of Hospitality Management, 37, 21-28.

Cogin, J. (2012). Are generational differences in work values fact or fiction? Multi-country evidence and implications. International Journal of Human Resource Management, 23 (11), 2268-2294.

Edwards, J. A., \& Billsberry, J. (2010). Testing a multidimensional theory of person-environment fit. Journal of Managerial Issues, 22 (4), 476-493. 
Edwards, J. R. (2008). Person-environment fit in organizations: An assessment of theoretical progress. Academy of Management Annals, 2 (1), 167-230.

Edwards, J. R., Cable, D. M., Williamson, I. O., Lambert, L. S., \& Shipp, A. J. (2006). The phenomenology of fit: Linking the person and environment to the subjective experience of person-environment fit. Journal of Applied Psychology, 91 (4), 802-27.

Feij, J. A., van der Velde, M. E. G., Taris, R., \& Taris, T. W. (1999). The development of person-vocation fit: A longitudinal study among young employees. International Journal of Selection and Assessment, 7 (1), 12-25.

Fishbein, M., \& Ajzen, I. (1975). Belief, attitude, intention, and behavior: An introduction to theory and research. Reading, MA: Addison-Wesley.

Glew, D. J. (2012). Effects of interdependence and social interaction-based person-team fit. Administrative Sciences, 2 (1), 26-46.

Harold, C. M., \& Ployhart, R. E. (2008). What do applicants want? Examining changes in attribute judgments over time. Journal of Occupational and Organizational Psychology, 81 (2), 191-218.

Hershatter, A., \& Epstein, M. (2010). Millennials and the world of work: An organization and management perspective. Journal of Business and Psychology, 25 (2), 211-223.

Highhouse, S., Lievens, F., \& Sinar, E. F. (2003). Measuring attraction to organizations. Educational and Psychological Measurement, 63 (6), 986-1001.

Jansen, K. J., \& Kristof-Brown, A. (2006). Toward a multidimensional theory of person-environment fit. Journal of Managerial Issues, 18 (2), 193-212.

Judge, T. A., \& Cable, D. M. (1997). Applicant personality, organizational culture, and organization attraction. Personnel Psychology, 50 (2), 359-394.

Kim, T.-Y., \& Kim, M. (2013). Leaders' moral competence and employee outcomes: The effects of psychological empowerment and person-supervisor fit. Journal of Business Ethics, 112 (1), 155-166.

Kristof, A. L. (1996). Person-organization fit: An integrative review of its conceptualizations, measurement, and implications. Personnel Psychology, 49 (1), 1-49.

Kristof-Brown, A. L., Zimmerman, R. D., \& Johnson, E. C. (2005). Consequences of individuals' fit at work: A meta-analysis of person-job, person-organization, person-group, and person-supervisor fit. Personnel Psychology, 58 (2), 281-342.

Lusch, R. F., Vargo, S. L., \& O’Brien, M. (2007). Competing through service: Insights from servicedominant logic. Journal of Retailing, 83 (1), 5-18.

Marcus, B., \& Wagner, U. (2015). What do you want to be? Criterion-related validity of attained vocational aspirations versus inventoried person-vocation fit. Journal of Business and Psychology, 30 (1), 51-62.

Nazir, N. A. (2005). Person-culture fit and employee commitment in banks. Vikalpa, 30 (3), 39-51.

Nunnally, J. C., \& Bernstein, I. H. (1994). Psychometric theory (3rd ed.). New York, NY: McGraw-Hill.

Oh, I.-S., Guay, R. P., Kim, K., Harold, C. M., Lee, J. H., Heo, C. G., \& Shin, K. H. (2014). Fit happens globally: A meta-analytic comparison of the relationships of person-environment fit dimensions with work attitudes and performance across East Asia, Europe, and North America. Personnel Psychology, 67 (1), 99-152.

Piasentin, K. A., \& Chapman, D. S. (2007). Perceived similarity and complementarity as predictors of subjective person-organization fit. Journal of Occupational and Organizational Psychology, 80 (2), 341-354

Phillips, J. M., Gully, S. M., McCarthy, J. E., Castellano, W. G., \& Kim, M. S. (2014). Recruiting global travelers: The role of global travel recruitment messages and individual differences in perceived fit, attraction, and job pursuit intentions. Personnel Psychology, 67 (1), 153-201.

Schlager, T., Bodderas, M., Maas, P., \& Cachelin, J. L. (2011). The influence of the employer brand on employee attitudes relevant for service branding: An empirical investigation. Journal of Services Marketing, 25 (7), 497-508.

Schmidt, J. A., Chapman, D. S., \& Jones, D. A. (2015). Does emphasizing different types of person-environment fit in online job ads influence application behavior and applicant quality? Evidence from a field experiment. Journal of Business and Psychology, 30, 267-282.

Seong, J. Y., \& Kristof-Brown, A. L. (2012). Testing multidimensional models of person-group fit. Journal of Managerial Psychology, 27 (6), 536-556. 
Solnet, D. J., Ford, R. C., Robinson, R. N. S., Ritchie, B. W., \& Olsen, M. (2014). Modeling locational factors for tourism employment. Annals of Tourism Research, 45, 30-45.

Swider, B. W., Zimmerman, R. D., \& Barrick M. R. (2015), Searching for the right fit: Development of applicant person-organization fit perceptions during the recruitment process. Journal of Applied Psychology, 100 (3) 880-93.

Werbel, J. D., \& Johnson, D. J. (2001). The use of person-group fit for employment selection: A missing link in person-environment fit. Human Resources Management, 40 (3) 227-240.

Wheeler, A. R., Buckley, M. R., Halbesleben, J. R. B., Brouer, R. L., \& Ferris, G. R. (2005). “The elusive criterion of fit" revisited: Toward an integrative theory of multidimensional fit. Research in Personnel and Human Resources Management, 24, 265-304.

Wilden, R., Gudergan, S., \& Lings, I. N. (2010). Employer branding: Strategic implications for staff recruitment. Journal of Marketing Management, 26 (1-2), 56-73.

\section{Acknowledgements}

The research reported in the paper is a part of a project supported by the National Science Centre, Poland under the Grant "Quality of work life in competitive potential development in the tourism industry" (DEC-2012/07/B/ HS4/03089). 